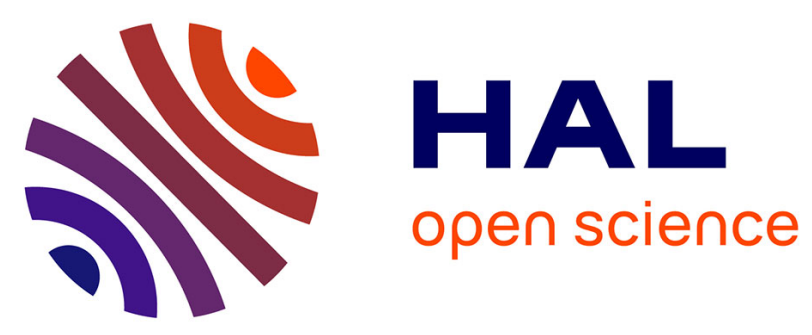

\title{
An Approach for Surfacing Hidden Intentions and Trustworthiness in Logistics Resource Sharing Networks
}

Morice Daudi, Klaus-Dieter Thoben, Jannicke Baalsrud Hauge

\section{To cite this version:}

Morice Daudi, Klaus-Dieter Thoben, Jannicke Baalsrud Hauge. An Approach for Surfacing Hidden Intentions and Trustworthiness in Logistics Resource Sharing Networks. 19th Working Conference on Virtual Enterprises (PRO-VE), Sep 2018, Cardiff, United Kingdom. pp.524-536, 10.1007/978-3-31999127-6_45. hal-02191148

\author{
HAL Id: hal-02191148 \\ https://hal.inria.fr/hal-02191148
}

Submitted on 23 Jul 2019

HAL is a multi-disciplinary open access archive for the deposit and dissemination of scientific research documents, whether they are published or not. The documents may come from teaching and research institutions in France or abroad, or from public or private research centers.
L'archive ouverte pluridisciplinaire HAL, est destinée au dépôt et à la diffusion de documents scientifiques de niveau recherche, publiés ou non, émanant des établissements d'enseignement et de recherche français ou étrangers, des laboratoires publics ou privés. 


\title{
An Approach for Surfacing Hidden Intentions and Trustworthiness in Logistics Resource Sharing Networks
}

\author{
Morice Daudi ${ }^{1}$, Klaus-Dieter Thoben ${ }^{2}$, Jannicke Baalsrud Hauge ${ }^{2,3}$ \\ ${ }^{1}$ Faculty of Science and Technology, Mzumbe University, Mzumbe, Tanzania \\ \{dmorice@mzumbe.ac.tz\} \\ ${ }^{2}$ Bremer Institut für Produktion und Logistik at the University of Bremen, Germany \\ $\{$ baa, tho\}@biba.uni-bremen.de \\ ${ }^{3}$ School of Engineering, Technology and Health, KTH, Royal Institute of Technology, Sweden
}

\begin{abstract}
Collaboration on sharing logistics resources aims to balance supply and demand of the idle, inefficiently, and underutilized resources. Although sharing is beneficial, many issues such as privacy, security, time, regulations, safety, biased reviews, and ratings hinder the sharing. Such problems procreate many uncertainties, which as a consequence, lead to low trust in sharing resources. Meanwhile, existing solutions such as trust and reputation mechanism, and online reviews and ratings incorporate the least consideration to monitor hidden intentions and behaviors of partners. Therefore, this paper proposes an approach to surface hidden intentions and trustworthiness of partners involved in sharing resources. The approach stands on cognitive principles to explore intentions and trustworthiness of suppliers and consumers of logistics resources. Application of the proposed approach is illustrated using industrial case extracted from ridesharing platform.
\end{abstract}

Keywords: Collaboration, intention, trustworthiness, resource sharing, logistics networks, cognitive systems, prediction.

\section{Introduction}

Collaboration in sharing resources is an approach to leverage multiple inefficiencies faced by individuals and organizations. It is a re-birth of traditional sharing, elevated by digital technologies. In logistics sector, for example, partners can share the vehicle trucks, warehouses, distribution centers, and machinery equipment [1]-[3] collaboratively. As well, human-beings are becoming part of shareable logistics resources because they provide the flexible workforce[4]. An overall goal of collaborative sharing is to balance demand and supply of idle and underutilized resources. Benefits of sharing resources include reducing costs and harms to the environment but also increase the efficiency of logistics services.

Efforts to share logistics resources encounter many difficulties, including tight regulations, perceived (existing) opportunism, and deceitful behaviors. Other impediments comprise the possibility of adverse outcomes such as theft, strangers, and intrusion of privacy [5]. On top of the outlined issue, the main impediment is the 
low level of trust. The little trust accrues from many sources including collaborative logistics processes and partner behaviors. In sharing resources, consumers need to trust that: supplier will deliver services according to reasonable standards; they will receive proper compensation in case of unmet expectations, and; their safety and security will be maintained [6]. Also, consumers need to trust the platform they use, as well as people they connect with [7]. Since sharing stands mainly on trust, its success has also to depend on building confidence and realistic expectations.

Similar to other forms of collaborative networks, resource sharing networks in logistics can rely on digital intermediating platforms. One goal of digital platforms is to reduce transactions costs incurred in intermediating suppliers and consumers. In particular, digital platforms facilitate and support: searching for partners; bargaining; reinforcing agreements and; evaluating (recommending) undertaken sharing transactions. Recommendation comprises mainly of reviews and ratings, which are used to generate reputation and trustworthiness. This paper acknowledges many works in literature, contributing on how to choose partners, enforce agreements, and evaluates (recommend) goods or services transacted.

Comparatively, partners' intention and trustworthiness featured in logistics resource sharing networks, as facilitated by digital platforms, rely also on reviews and ratings. One main drawback of such reviews and ratings is that some do not reflect reality. There are limitations, which feature in a perspective of biases [8], [9], low incentive to provide ratings, skewness towards positive rating, and unfair ratings [9]. There are many works in literature contributing to on how to improve limitations of online reviews and ratings (such as [10]-[13]). This paper, however, contributes to resolving this problem differently. The paper focuses on establishing a proposition that can complement some impediments in reviews and ratings. In particular, it proposes a cognitive approach that can surface hidden issues underlying logistics networks of sharing. The approach stands on cognitive systems to scrutinize patterns of suppliers and consumers of idle/underutilized logistics resources. The proposed approach provides headlights related to a party's intention and trustworthiness, which are difficult to realize under existing mechanics in online reviews and ratings.

The remainder of the paper consists of six sections. Section 2 describes and discusses shareable logistics resources, trust in business relationships. Whereas section 3 defines a methodology of the paper, section 4 explains social behavior, intentions, and how they link to cognitive systems. Section 5 presents a proposed cognitive approach whose illustrative application appears in section 6 . The paper ends in section 7 by providing concluding remarks and future works.

\section{Trustworthiness in Sharing Logistics Resources}

The present section describes and discusses resource sharing in logistics (subsection 2.1) as well as trust-building in networks supporting the sharing (subsection 2.2). 


\subsection{Resource Sharing in Logistics}

One may categorize shareable resources in logistics as the physical, non-physical, and human assets. Sharing of the physical resources entails a joint usage of tangible assets such as the vehicles (trucks), warehouses, distribution centers, and machinery equipment [1]-[3]. Such infrastructures are potential to share because they frequently remain idle or underutilized. Additionally, sharing of the outlined infrastructures is beneficial because deploying them primarily on an individual basis is relatively difficult and expensive. The second category, non-physical resources, refer to intangible assets such as the data, information, supporting processes [14] and logistics services. Information, in particular, is a non-physical shareable resource [1], [2] that drives and makes logistics systems functional.

Partners may also share logistics services offered under cloud computing. The cloud computing services comprise of Platform as a Service (PaaS), Software as a Service (SaaS), and Logistics Business Process as a Service (BPaaS). The PaaS is a layer of clouds that provide vital services in the form of a framework that can be used to simulate various logistics scenarios [15]. Equally, the SaaS may, for example, offer shareable digital platforms to facilitate matchmaking among suppliers and consumers of shareable assets. Additionally, the BPaaS facilitates a bundling of several logistics cloud services from different vendors and suppliers, to produce a directly useable logistics turnkey application [16]. Moreover, sharing is seen to emerge in human resources. In recent years, skills and personal time seems offered through shareable modes under the facilitation of digital platforms [4]. For example, in the US, about $34 \%$ of the workforce work as freelancers, revealing that there is a fundamental shift in attitudes about flexibility in workforces [4].

\subsection{Trust-building in Resource Sharing Networks}

Trust-building, especially in business relationships may be upheld by various processes, as well as determined using diverse perspectives. According to [17], development of trust in business relationships draws in the calculative, predictive, capability, intentionality, and transference processes. The predictive and intentionality processes appear to clarify and backup better the context of intentions and trustworthy, and; may contribute to understanding undisclosed intentions and trustworthiness of suppliers and consumers who share logistics resources. These processes are defined as follows. Trust-building under the [17]: predictive process relies on developing confidence by prognosticating a target's behavior on account of repetitive interactions, and; intentionality process requires evaluating motivations of the target. One can also express this motivation in the form of actions and intentions. In this context, therefore, a party can be trusted if its actions and intentions are perceived as benevolent by the perceiver [18]. Besides the trust-building processes, trust in business relationships also originates from specific determinants.

Trust in business relationships is determined by [19]: partners' social interactions; institutionalized processes and routines, and; supplier selection processes. These determinants feature mainly in digital platforms. From searching to evaluation, 
partners interact in many ways under the guidance of an intermediating company. The intermediating company is expected to have already ruled out processes and routines, which suppliers and consumers will follow. The supplier selection process, for example, can follow a widely used criterion such previous performance. Equally, suppliers may be selected depending on their track record of performance [19].

In the matter of structure, collaborative networks in which sharing networks befall undergo three phases, namely: selection, enforcement, and evaluation. The first phase requires both the supplier and consumer to exchange information concerning the supply and demand of shareable logistics resources. In this exchange, attributes of a specific resource, its conditions, as well as amount of demand have to be provided. Additionally, reputation and trust that can lead partners to share a resource depend fundamentally on previous reviews and ratings. In the second phase, subject to applied interactions protocols, the supplier and consumer bargain and agree to a deal that is to be transacted. Agreements to implement may benefit from the power of cyber-physical systems and internet of things especially in tracking progress. Different from previous phase, trust is built by anticipating outcomes to resource sharing transactions. One way to unveil this anticipation is to simulate particular sharing scenarios. In the third phase, operations on sharing logistics are completed. Upon completion, suppliers and consumers review and rate each other. Provided reviews and ratings constitute feedbacks to related transactions they had undertaken. The feedback also updates previous reviews and ratings.

\section{Methodology}

The present paper follows a methodology sequenced in three stages. First, the aspect of reputation and trust mechanisms underlying online transactions in e-commerce are adapted to constitute a basis of establishing intentions and trustworthiness in resource sharing networks. These aspects are then linked to cognitive systems in humans and later borrowed into a context of computational settings. The cognitive systems are further enriched by principles originating from social psychology theory, such as the theory of planned behavior. Since interactions of suppliers and consumers exhibit a social phenomenon, principles of social exchange are as well applied. Afterward, the cognitive approach to monitor interactions of suppliers and consumers is conceived. Finally, an illustrative application that draws from industrial cases is provided.

\section{Reputation and Trustworthiness in a Cognitive Perspectives}

This section discusses limitations of online trust mechanisms and strengthens a need to embed cognitive systems in digital platforms (subsection 4.1). Subsection 4.2 presents cognitive principles that guide conception of the cognitive approach. 


\subsection{Reputation and Trust in e-Commerce and Resource Sharing Platforms}

E-commerce platforms enjoy the self-regulation (decentralized) and institutional (centralized) controls in safeguarding online sales and purchases. They also benefit intermediation, for example, to recover economic values (such as money) from incomplete or unfulfilled transactions. Besides the economic recovery, reputation and trust between trading partners are established using online reviews and ratings. Even though, as outlined earlier, such reviews and ratings suffer a range of deceitful manipulations. For example, authors in [20] emphasize that overall numerical ratings typically used in review systems may not ideally indicate satisfaction of customers. In regard to unfairness, common biases in user-generated online ratings include the simple bias, under-reporting bias, and sequential bias [8]. In spite of these challenges, yet there is a lack of a commonly agreed conceptual model to detecting deceitful manipulations [21] in reviews and ratings. Although reputation mechanisms in ecommerce carry limitations, still they can be adapted by digital platforms in resource sharing networks. Except that, such mechanisms need to be complemented with, for example, cognitive systems that monitor in background interaction activities of the suppliers and consumers. For this reason, this paper proposes an approach to complement such biased reviews and ratings.

For cognitive systems to detect susceptible intentions and trustworthiness from review and ratings, there must exist enabling environments. Enabling environments may be drawn by considering differences between transactions underlying ecommerce and sharing networks in logistics. Currently, this paper provides three differences. First, while e-commerce involves sales, purchases, and delivery of goods and services, resource sharing concerns a joint usage of logistics assets. Second, in ecommerce, products or services are purchased mostly once by the same individual for an extended period, while in resource sharing, the same resource can be re-shared by the same consumer in short period. Third, in e-commerce, the seller is mostly the trustee, whereas in resource sharing both supplier and consumer become trustor and trustee simultaneously ${ }^{1}$.

In a context of outlined differences, resource sharing opens additional chance to examine whether reviews and ratings provided were manipulated or not. For example, if consumer rates the supplier positively, it is expected that he will prefer to share a resource with the same supplier when another opportunity unfolds. If this is missing in environments where supplier and consumer have all possibilities to re-share, it becomes a signal that previous reviews and ratings may have carried hidden intentions. In this case, therefore, one way to safeguard resource sharing in a context of digital platforms is to embed cognitive systems that can monitor in background interactions activities of suppliers and consumers. Expectedly, such cognitive systems have to provide hidden headlights regarding intentions and trustworthiness of both the suppliers and consumers.

\footnotetext{
${ }^{1}$ Meaning that, trust is placed mostly in both the supplier and consumer
} 


\subsection{Behavior and Cognitive Systems in Building Trust}

Prediction as the trust-building process hinges on anticipating behaviors of a target. The anticipation may be unveiled by scrutinizing experience accumulated under repetitive interactions of actors. In digitally mediated interactions, the accumulation, processing, foreseeing, and understanding of intentions and trustworthiness can be attained using cognitive systems. Cognitive systems refer to the application of humanlike characteristics to convey and manipulate ideas [22]. In computing arena, people refer to cognitive systems as cognitive computing. To its advantage, cognitive computing helps to illuminate headlights that were previously invisible, thus, allowing people to make more informed decisions [23] as well as learning. In a standpoint of resource sharing networks, cognitive systems may assist to explore and discover partners' hidden intention and trustworthiness, which are difficult to unfold using programmable systems.

The models of social psychology may guide the ability to foresee, detect and understand the intentions and trustworthiness of partners. Towards this, the Theory of Planned Behavior (TPB) in [24] assumes that people do what they intend to do and do not do what they do not intend. Given this, intention sheds light on the possibility of actors to perform a particular action. The author [24] emphasizes further that the most immediate and vital predictor of a person's behavior is his/her intention to perform it. Usually, intentions unfold into behavior when people carry out their actions. Henceforth, behavior as a consequent of the intention is the manifest, observable response in a given situation concerning a given target [25]. The intention and behavior can be identified by patterns of interactions, for example, by monitoring actors' interaction activities [26] in the background. Even though, it is vital to take note regarding dynamics of intentions. The effects of time and new information drive dynamics of intentions [27]. One crucial issue in concern is about how to apply principles of social psychology to enrich cognitive computing to complement trustbuilding under aspects of intentions and trustworthiness. This application constitutes a foundation to the proposed approach.

Furthermore, trust-building, as enabled by cognitive systems, is also grounded in social exchange principles. According to [28], for all actions taken by persons, the more often a particular action of a person is rewarding, the more likely the person is to perform that action again. Meaning that partners with previous rewarding actions carry high possibility to re-engage in future resource sharing endeavors. Henceforth, by drawing from principles of intention and rewarding actions, this paper proposes an approach that can surface hidden intentions intrinsic in biased reviews and ratings. To exemplify this in brief, if one party rates another one positively, it is declaring its intention to engage in future resource sharing ventures. This intention can be confirmed or disconfirmed once another chance to re-share a resource unfolds.

\section{Proposed Cognitive Approach}

The proposed cognitive approach takes into account provisions discussed in previous sections. It mainly harnesses requirements on social behavior to rewarding actions, 
intention, as well as cognitive systems. Equally, the approach rests on the assumption that at least one previous interaction between specific supplier and a consumer exists. A related hypothesis is to foresee that interactions between the resource supplier and consumer will re-occur in future engagements. Meaning that the same consumer may re-share the same resource with the same supplier when another opportunity appears. This assumption is distinct from e-commerce, where consumers can rarely repurchase products or services (e.g., electronic equipment, fashion, and sporting goods) from the same seller.

In its current form, the cognitive approach focuses on collecting and measuring the following features. First, it measures a number of resources offered; acceptances and rejections made by suppliers and consumers, and; offers seen by supplier and consumer. Second, the cognitive approach also collects as well information related to externally influencing factors. For example, information related to capacity, quality and location of a resource, price (per time/space/slot), and in case of a vehicle truck, its origin, and destination. These features get analyzed to provide useful insights. Remaining part of the approach advances as follows.

The platform supporting sharing of logistics resources comprises of many suppliers and consumers (Fig. 1). A resource publicized by suppliers is made available to multiple consumers, and various suppliers can provide similar offers.
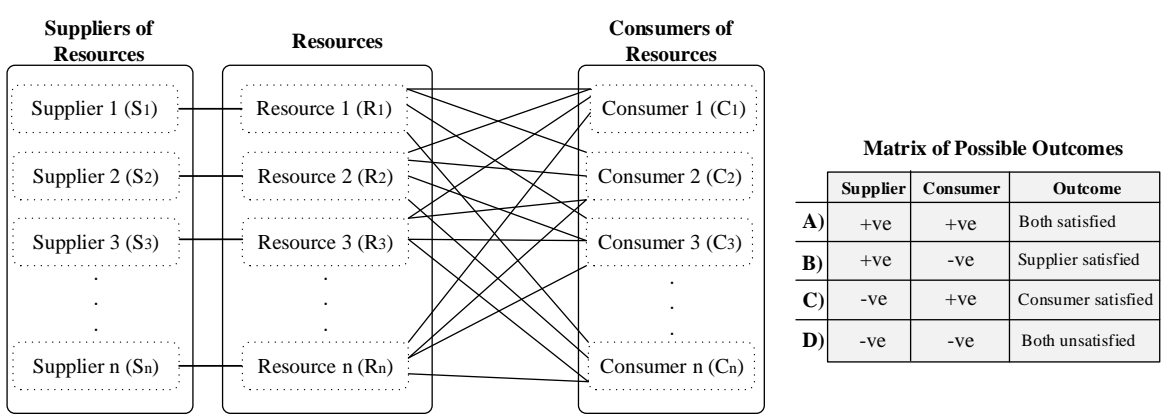

Fig. 1. Matching suppliers and consumers who share resources - a simplified view

Multiple offers enable consumers to access many options in searching and selecting a preferred supplier. For every possible search, the cognitive approach (system) records information about the resource, supplier, and consumer. It is worthy to note that, the supplier must have already described the resource in a manner desired, for example, by providing its capacity, location, price per time/space/slot, and in case of a vehicle truck, its origin, and destination. Afterward, interested consumers begin to interact with suppliers to negotiate a deal, and meanwhile; the system monitors in the background such interactions (Fig. 2). The system checks whether there exist supplier and consumer who had transacted earlier. If found, it checks again whether consumer $\mathrm{C}_{\mathrm{x}}$ opts to transact with supplier $\mathrm{S}_{\mathrm{x}}$. The outcome is twofold: re-transacting or not. The choice to re-transact has to take into account that other influencing factors are held constant. Meaning that conditions (such as price which $S_{\mathrm{x}}$ declare) must be in a range that is similar or lower than those of remaining suppliers. Afterward, when supplier agrees to transact, the system rechecks a trend of the $S_{\mathrm{x}}$ to accept/bypass 
interested consumers, and similarly, the pattern of the $C_{x}$ to take/reject offers from suppliers. For every termination or agreement reached, the system re-checks its stored history to draw helpful headlights. The check, mapping, and headlights to be derived are summarized in a matrix of possible outcomes (Fig. 1) as follows:

a) Under normal circumstances, the expectation is that the two parties will retransact. This expectation aligns to an attitude toward behavior (TPB), by which both the supplier and consumer had valued previous engagement positively. Equally, as per perceived behavioral control, consumer had previously perceived that the supplier has ability to perform a transaction (provide resource). However, if no party seems interested in re-transacting, and external factors are least influential, then it may imply that the previous reviews and ratings were unfair. The external factors constitute what the TPB refers to as control beliefs, which may facilitate or impede participation of supplier and consumer. Also, the implication rests on a principle that human-beings tend to repeat past rewarding actions while avoiding those costly ones. In addition, there might be an untold story that has to be unfolded between concerned supplier and consumer, which the reviews and ratings did not reveal;

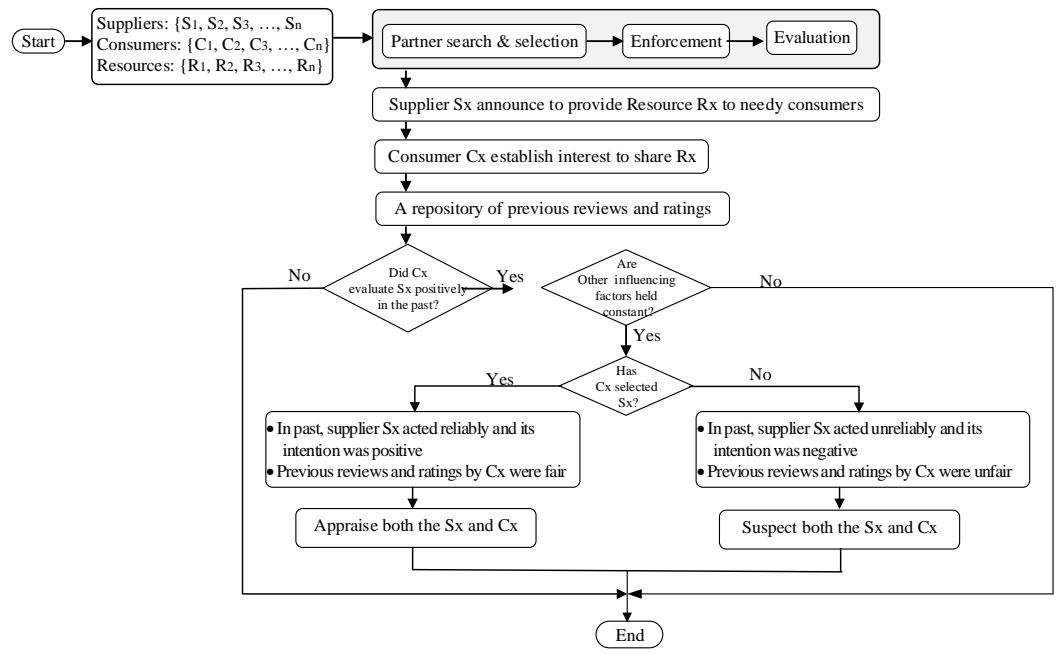

Fig. 2. A cognitive approach to surface hidden intention and trustworthiness

b) It is expected that consumer $C_{x}$ will avoid to re-transact with supplier $S_{x}$ because it was unsatisfied in prior engagements. Concordant to attitude toward a behavior (in TPB), consumer values negatively performance of the supplier by referring to previous engagements. Unlike the consumer $C_{x}$, the supplier $S_{x}$ will be interested in re-transacting with consumer $C_{x}$ because it valued previous engagement positively. However, if observed outcomes are beyond such expectations, then the reviews and ratings from one or both parties were possibly biased;

c) Expectation along this outcome are similar to those in (b), except that this time the supplier $S_{x}$ was unsatisfied;

d) Since neither party was satisfied in previous engagements, it is expected that the supplier $S_{x}$ and consumer $C_{x}$ will not re-transact. 
These headlights collected in a silent mode may later be published along with the supplier's and consumer's profile. The goal is to indicate intentions and trustworthiness of suppliers/consumers beyond those depicted in reviews and ratings.

\section{Illustrative Application}

Currently, the paper does not provide an empirical validation or evaluation of the proposed approach. It discusses illustrative example of the application of the cognitive approach. However, illustrating application by using industrial case is challenging due to lack of sharing practices, which entail likelihood of consumers to re-transact with the same supplier. As well, data about sharing scenarios involving assets such as vehicle trucks and warehouses is currently difficult to obtain. On account of this, the illustrative application is attained using ridesharing scenarios. The ridesharing offers an opportunity for suppliers and consumers of idle space in personal cars to re-share. Following this, one anonymous platform that offers ridesharing is used because suppliers and consumers of idle space in personal cars may attain a chance to re-share. The illustrative case study progresses as follows.

The list of suppliers offering shareable resources (idle spaces) between common source and destination areas is searched in the platform. A total of seven suppliers whose reviews exceed 100 are selected randomly. The selection seeks to ensure that, at least each supplier may have had a chance to re-share with the previous consumer. Afterward, analysis of the reviews is conducted to figure out consumers who have had ridesharing with the same supplier, at least, for more than once (Table 1). Equally, some years in which the supplier has been in business, its average rating, and ridings (sharing) are extracted.

By assuming that other externally influencing factors (if any) were held constant; results in Table 1 may surface many issues. For example, the suppliers $S_{1}, S_{4}$, and $S_{5}$ had an almost equal number of average sharing (annually) as well as comparable average ratings. Under normal circumstances, such suppliers are expected to have scored a similar amount of re-sharing. However, this is different because the percentage of consumers re-sharing with suppliers $S_{1}, S_{4}$, and $S_{5}$ is $19.4 \%, 5.2 \%$, and $1.6 \%$, respectively. These results may convey an implication that many consumers evaluating the supplier $S_{1}$ had positive intention in their reviews and ratings.

Table 1. Summary of consumers' reviews and ratings on suppliers

\begin{tabular}{ccccccc}
\hline Supplier & $\begin{array}{l}\text { No. of } \\
\text { years }\end{array}$ & $\begin{array}{l}\text { Avg. } \\
\text { rating }\end{array}$ & $\begin{array}{l}\text { No. of } \\
\text { sharing }\end{array}$ & $\begin{array}{l}\text { Avg. } \\
\text { sharing/year }\end{array}$ & $\begin{array}{l}\text { Consumers } \\
\text { sharing }\end{array}$ & $\begin{array}{l}\text { Consumers } \\
\text { re-sharing }\end{array}$ \\
\hline $\mathrm{S}_{1}$ & 8 & 4.9 & 352 & 44 & 402 & $78(19.4 \%)$ \\
$\mathrm{S}_{2}$ & 4 & 4.8 & 116 & 29 & 106 & $0(0.0 \%)$ \\
$\mathrm{S}_{3}$ & 1 & 4.9 & 110 & 110 & 126 & $4(3.2 \%)$ \\
$\mathrm{S}_{4}$ & 5 & 4.9 & 221 & 44 & 154 & $8(5.2 \%$ \\
$\mathrm{S}_{5}$ & 4 & 4.9 & 171 & 43 & 122 & $2(1.6 \%)$ \\
$\mathrm{S}_{6}$ & 7 & 4.9 & 146 & 21 & 201 & $14(7.0 \%)$ \\
$\mathrm{S}_{7}$ & 7 & 4.4 & 256 & 37 & 247 & $28(11.3 \%)$ \\
\hline
\end{tabular}


In addition, it seems that reviews and ratings by such consumers were mostly fair because many of them opted to re-share with their previous supplier. Correspondingly, the supplier $S_{1}$ appears to have exhibited behavior which is seemingly trusted by consumers. Unusual intention and trustworthiness appear in supplier $S_{2}$. Despite high average sharing per year, yet supplier $S_{2}$ had no any consumer opting to re-share with it, although its average rating is relatively high (4.8). The absence of re-sharing may imply that hidden intentions of consumers' reviews/ratings on the supplier $S_{2}$ were negative.

Further useful headlights may be derived by considering consumers who appeared to switch among suppliers. Towards attaining this, further analysis was undertaken to figure out if there exist resource consumers who have had ridesharing by more than one resource supplier (consumer shift). Figure 3 presents corresponding results. For example, out of 247 consumers who had ridesharing with supplier $S_{1} ; 8$ had ridesharing with $S_{2} ; 10$ had ridesharing with $S_{3} ; 11$ had ridesharing with $S_{4} ; 6$ had ridesharing with $S_{5}, 10$ had ride sharing with $S_{6}$, and; 10 had ridesharing with $S_{7}$.

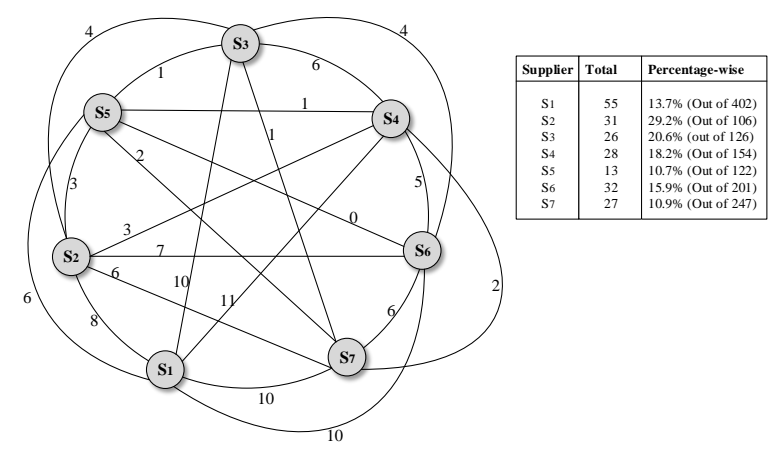

Fig. 3. Number of consumers who shift among suppliers

Assuming that customers prefer to attach themselves to a good supplier, results reveal that suppliers $S_{1}(13.7 \%), S_{5}(10.7 \%)$, and $S_{7}(10.9 \%)$ managed to retain many customers. However, the situation is different to others, for example, supplier $\mathbf{S}_{2}$ whose percentage of customers shifting to other suppliers is relatively large (29.2\%). Under this circumstance, it seems that many consumers who have had ridesharing with supplier $\mathrm{S}_{2}$ had no intention and trustworthiness to re-engage with that supplier, although their ratings were positive. This situation is different from supplier $\mathrm{S}_{1}$ who had the highest number of consumers participating in ridesharing (Table 1) while having a low number of consumers who shift to other suppliers (Fig. 3).

As outlined before, these industrial cases have been provided to satisfy illustrative application of the cognitive approach. In view of this, used instances may contain limitations. For example, one flaw is that re-sharing in ridesharing may be affected many factors such as prices, date of travel, as well as the origin and destination. As far as the data used did not capture such issues, findings discussed in this section may be inconclusive. It might be that some consumers did not engage in re-sharing because their previous suppliers had changed, for example, common origins and destinations. Second, it may be that the offered ridesharing was unconducive to them, in terms of date and time of traveling, as well as price. If all these parameters had been captured 
since at beginning, it would help to enrich reported insights. It is suggested that these issues may be dealt with when undertaking empirical validation or evaluation of the proposed approach. Moreover, building on reported flaws, the present work do not compare its results to the state of the art. This is because data used in illustrative example lack some features. Correspondingly, extended evidence to justify selection of measurable features will be part of research works that succeeds the present paper.

\section{Conclusion and Future Works}

Collaboration in sharing logistics resources entails a joint usage of assets to attain mutual benefits. It can usually comprise of partnerships which are forged at short notice, and whose lifespan is short-lived. Digital platforms support these partnerships to intermediate suppliers and consumers of shareable resources. These platforms, similar to those in e-commerce, depend mainly on reputation generated from reviews and ratings. One major drawback of online reviews and ratings is unfairness attributed to many sources. The unfair (biased) reviews and ratings convey signals, which can misguide the individual to trust. To this end, this paper has proposed an approach to surface intentions and trustworthiness hidden in reviews and ratings of both the suppliers and consumers. The approach can also be applied to monitor intentions and trustworthiness among platforms, for example, by scrutinizing why consumers and suppliers shift from one platform to another. For this to be possible, the approach has to be embedded in a platform of platforms (regulator platform). Future research works extend to the following. First, modeling a mechanism for improving rates and reviews. Second, carrying out empirical validation or evaluation of the cognitive approach (mechanism). Such empirical works can stand on various methods such as serious gaming and multi-agent systems simulation.

\section{References}

1. Gci, Capgemini.: 2016 Future Supply Chain. Serving Consumers in a Sustainable Way. $\mathrm{http} / / /$ supplychainmagazine.fr/TOUTE-INFO/ETUDES/GCI_Capgemini-SC2016.pdf(2008)

2. Gorenflo, N.: The New Sharing Economy. Shareable Magazine. https://www.shareable.net/blog/the-new-sharing-economy (2010)

3. Weinelt, B.:Digital Transformation of Industries: Logistics Industry. http://reports.weforum.org/digital-transformation (2016)

4. Gesing, B.: Sharing economy logistics: Rethinking logistics with access over ownership. Troisdorf, Germany. http://www.dhl.com (2017)

5. Buczynski, B.: Sharing is Good: How to Save Money, Time and Resources through Collaborative Consumption. Gabriola Island, BC Canada: New Society Publishers (2013)

6. Goudin, P.: The Cost of Non- Europe in the Sharing Economy. Brussels: European Union. http://doi.org/10.2861/26238 (2016)

7. Wosskow, D.: Unlocking the sharing economy: An independent review. Department for Business, Innovation and Skills, UK Government. https://www.gov.uk/government/publications (2014) 
8. Sikora, R., You, L.: Effect of Reputation Mechanisms and Ratings Biases on Traders' Behavior in Online Marketplaces. Journal of Organizational Computing and Electronic Commerce, 24(1), 58-73 (2014)

9. Josang, A., Ismail, R., Boyd, C.: A survey of trust and reputation systems for online service provision. Decision Support Systems, 43(2), 618-644 (2007)

10.Luca, M.: Designing Online Marketplaces: Trust and Reputation Mechanisms. Cambridge, MA http://www.nber.org/papers/w22616.pdf (2006)

11.Akoglu, L., Faloutsos, C., Chandy, R., Faloutsos, C.: Opinion Fraud Detection in Online Reviews by Network Effects. In Proceeding of the $7^{\text {th }}$ International AAAI Conference on Weblogs and Social Media (pp. 2-11). Palo Alto: The AAAI Press (2013).

12.Xu, C., Zhang, J.: Collusive Opinion Fraud Detection in Online Reviews. ACM Transactions on the Web, 11(4), 1-28 (2017)

13.Mukherjee, S., Dutta, S., Weikum, G.: Credible review detection with limited information using consistency features. Lecture Notes in Computer Science, 195-213 (2016)

14.Pomponi, F., Fratocchi, L., Tafuri, S. R. (2015). Trust development and horizontal collaboration in logistics: a theory based evolutionary framework. Supply Chain Management-an International Journal, 20(1), 83-97 (2015)

15.Schuldt, A., Hribernik, K. A., Gehrke, J. D., Thoben, K.-D., Herzog, O.: Cloud Computing for Autonomous Control in Logistics. 40th Annual Conference of the German Society for Computer Science. Leipzig, Germany, September 27-October 1, 2010. pp, 305-310.

16.ALICE.: Information Systems for Interconnected Logistics: Research \& Innovation Roadmap. https://www.etp-logistics.eu/wp-content/uploads/2015/08/W36mayo-kopie.pdf (2014)

17.Doney, P. M., Cannon, J. P.: An Examination of the Nature of Trust in Buyer-Seller Relationships. Journal of Marketing, 61(2), 35-51 (1997)

18.Lindskold, S.: Trust development, the GRIT proposal, and the effects of conciliatory acts on conflict and cooperation. Psychological Bulletin, 85(4), 772-793 (1978)

19.Dyer, J. H., Chu, W.: The Determinants of Trust in Supplier-Automaker Relationships in the U.S., Japan and Korea. Journal of International Business Studies, 31(2), 259-285 (2000)

20.Racherla, P., Connolly, D. J., Christodoulidou, N.: What Determines Consumers' Ratings of Service Providers? An Exploratory Study of Online Traveler Reviews. Journal of Hospitality Marketing and Management, 22(2), 135-161 (2013)

21.Hu, N., Bose, I., Koh, N. S., Liu, L.: Manipulation of online reviews: An analysis of ratings, readability, and sentiments. Decision Support Systems, 52(3), 674-684 (2012)

22.High, R.: The Era of Cognitive Systems: An Inside Look at IBM Watson and How it Works. International Business Machines Corporation. http://www.redbooks.ibm.com/redpapers/pdfs/redp4955.pdf (2012)

23.Kelly, J. E.: Cognition and the future of knowing: How humans and machines are forging a new age of understanding. https://www.research.ibm.com/software/IBMResearch/multimedia/Computing Cognition WhitePaper.pdf (2015)

24.Sheeran, P.: Intention-Behavior Relations: A Conceptual and Empirical Review. European Review of Social Psychology, 12(1), 1-36 (2002)

25.Ajzen, I.: Theory of Planned Behavior. http://people.umass.edu/aizen/tpb.diag.html\#nulllink (2006)

26.Sherchan, W., Nepal, S., Paris, C.: A Survey of Trust in Social Networks. ACM Computing Surveys, 45(4), 47-47:33 (2013)

27.Ajzen, I.: From Intentions to Actions: A Theory of Planned Behavior. Action Control, 1139 (1985)

28.Homans, G. C.: Social Behaviour: Its Elementary Forms (Rev. ed.). New York: Harcourt Brace Jovanovich, Inc.(1974) 